\title{
Leucemia mieloide aguda secundária à trombocitemia essencial na infância
}

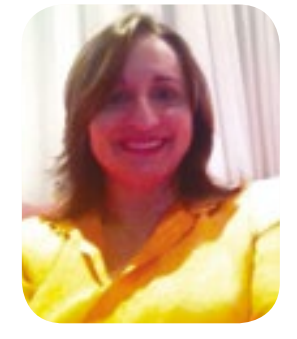

\section{INTRODUÇÃO}

A trombocitemia essencial ou trombocitose essencial é uma desordem mieloproliferativa crônica, caracterizada pela proliferação clonal de megacariócitos na medula óssea (mo), levando ao aumento persistente das plaquetas circulantes, com rearranjo brc/abl negativo. o nível plaquetário encontrado na doença é acima de $400 \times 10^{\wedge} 9 / /$, clinicamente cursando com esplenomegalia e episódios trombóticos e/ou hemorrágicos, entretanto na infância geralmente é assintomático. ${ }^{1-5}$

A incidência da doença é rara e a idade média ao diagnóstico está entre 50 e 60 anos, sendo um achado extremamente incomum na infância, com prognóstico bom na fase adulta e reservado na faixa etária pediátrica. ${ }^{6}$

A Trombocitemia Essencial (TE) pode estar associada a outras doenças mieloproliferativas crônicas, como a Leucemia Mielóide Crônica (LMC), Policitemia Vera (PV) e Mielofibrose Primária (MFP). O tratamento da TE consiste em terapia imunossupressora e a droga de $1^{\text {a }}$ linha mais utilizada no tratamento é a hidroxiureia. O Analegride e o alfa-Interferon funcionam como drogas de $2^{\mathrm{a}}$ linha no tratamento da TE.

O bom prognóstico depende do diagnóstico e tratamento precoces. Porém, a TE é grave e potencialmente fatal. A transformação em PV, MF e LMA é rara, sendo esta ao redor de $1,4 \%$ e pode demorar de 1,7 a 16 anos para ocorrer. Alterações citogenéticas são raras. ${ }^{7}$

\section{CASO CLÍNICO}

Paciente, D.S.S., 13 anos, sexo masculino, natural e procedente de Salvador, negro, previamente hígido, procurou o serviço médico em emergência pediátrica (fevereiro de 2013) com quadro febril (até $39^{\circ} \mathrm{C}$ ), sem sintomas associados, com 3 a 4 picos diários. Ao exame físico, sem foco infeccioso aparente, BEG, LOTE, palidez cutâneo-mucosa, fáceis atípicas, braços e pernas anormalmente longos e esplenomegalia; na época pesava $48 \mathrm{~kg}$ e media $1,79 \mathrm{~m}$. Na realização de exames de investigação foi detectado anemia e trombocitose, liberado com sintomáticos e encaminhado para avaliação hematológica. Chegou ao hospital Santa Izabel em maio de 2013, com trombocitose persistente e progressiva nos três meses antecedentes, presença de nódulos subcutâneos nas pernas, dedos e no abdômem, que desapareciam espontaneamente, acompanhados de dor no dorso do pé (secundária a eritromelalgia), sem outra sintomatologia associada e história de tromboses ou AVCs prévios. Realizado hemograma seriado, biópsia de medula óssea, avaliação genética e biologia molecular, cujos resultados seguem:

Hemograma: $\mathrm{Hb}=9.1$ ( $4 \%$ eritroblastos), Leuco = 20.200 (bastão $1 \%$, segmentado $71 \%$, linfócitos $9 \%$, monócitos $17 \%$, eosinófilos $2 \%$ ), plaquetas - 2960.000 .

Eletroforese de $\mathrm{Hb}$ : normal, sorologias sem alterações, avaliação endócrina: função tireoidiana normal, TC de crânio: microadenoma intraselar $(0,8 \mathrm{~cm})$.

Biópsia: hiperplasia megacariocítica com elementos displásicos e fibrose reticulínica sugerindo trombocitemia essencial.

Cariótipo: normal.

Biologia molecular: BCRABL: negativo e JAK 2: negativo.

Evoluiu com aumento progressivo da trombocitose. Em 31/07/2013 iniciou com hidroxiureia conforme protocolo vigente, evoluindo com melhora clínica e laboratorial (normalização do nível plaquetário).

Quadro 1. Hemogramas

\begin{tabular}{cccc}
\hline \hline DATA & HEMOGLOBINA & PLAQUETAS & LEUCÓCITOS \\
$22 / 05 / 2013$ & 9,0 & 3.969 .000 & 25.000 \\
$31 / 05 / 2013$ & 9,8 & 4.052 .000 & $28.200($ SEG=79\%) \\
$14 / 08 / 2013$ & 8,6 & 1.503 .000 & $17.200($ SEG $=73 \%)$ \\
$21 / 08 / 2013$ & 8,6 & 1.472 .000 & $13.200($ SEG $=72 \%)$ \\
$04 / 09 / 2013$ & 9,3 & 1.320 .000 & $11.500($ SEG $=72 \%)$
\end{tabular}




\begin{tabular}{lccc}
$18 / 09 / 2013$ & 8,8 & 874.000 & $10.4000($ SEG $=80 \%)$ \\
$23 / 10 / 2013$ & 8,9 & 396.000 & $8.400(\mathrm{SEG}=82 \%)$ \\
$04 / 12 / 2013$ & 9,2 & 331.000 & 2.600 \\
$08 / 01 / 2014$ & 10,3 & 255.000 & 2.800 \\
$19 / 03 / 2014$ & 9,4 & 271.000 & $3.200(\mathrm{SEG}=52 \%)$ \\
$12 / 05 / 2014$ & 10,5 & 170.000 & $2.340(\mathrm{SEG}=21 \%)$ \\
$14 / / 07 / 2014$ & 10 & 340.000 & $3.240(\mathrm{SEG}=72 \%)$ \\
$08 / 06 / 2014$ & 11,8 & 540.000 & $3.250(\mathrm{SEG}=68 \%)$ \\
$24 / 11 / 2014$ & 12,2 & 257.000 & $4.150(\mathrm{SEG}=65 \%)$ \\
$09 / 02 / 2015$ & 12,1 & 725.000 & $2.270(\mathrm{SEG}=68 \%)$ \\
$07 / 05 / 2015$ & 12,2 & 284.000 & 5.110 \\
$13 / 07 / 2015$ & 12,3 & 826.000 & $4.850(\mathrm{SEG}=75 \%)$ \\
$22 / 10 / 2015$ & 11,6 & 418.000 & \\
$21 / 01 / 2016$ & 8,8 & 393.000 & \\
\hline
\end{tabular}

Fonte: Prontuários HSI

Seguiu assintomático até 10/12/2015, quando iniciou quadro de febre com dor retroesternal. Permaneceu internado, tendo sido afastado tromboembolismo pulmonar; evoluiu com pancitopenia (necessidade transfusional), desenvolvendo quadro de Leucemia Mieloide Aguda em março de 2016

Imunofenotipagem medular: $61 \%$ de células $\mathrm{CD} 45+$ que coexpressam os antígenos de células precursoras (HLADR+/++ e CD34++), mieloides (CD33++/+++, CD13++/+++, MPO+ e CD1117++/+++). A pesquisa dos antígenos linfoide $B$ (citCD19 e citCD79a), Calla (CD10), linfoide T (CD2, CD7 e citCD3), mieloide (CD15), monocíticos(CD14 e CD64) e CD11b resultou negativa. $O$ perfil imunofenotípico demonstra tratar-se de células imaturas da linhagem mieloide. De acordo com a morfologia, imunofenótipo e dados clínicos, esses dados são compatíveis com Leucemia Mieloide Aguda Secundária.

Biópsia de medula óssea:

- Laudo anatomopatológico: microscopia: secções de medula óssea coradas em HE, PAS, Picro-Sirius, Reticulina e Perls com celularidade aumentada $(100 \%)$, devido à proliferação de células com aspecto imaturo, predominantemente, em meio a elementos das três séries hematopoiéticas. A coloração para ferro (Perls) foi negativa. Há aumento discreto da trama reticulínica. Conclusão: medula óssea hipercelular com proliferação de células imaturas.

- Laudo imuno-histoquímico: CD 20 (Clone L26, Dako): NEGATIVO nas células neoplásicas. CD 3 (Polyclonal, Dako): NEGATIVO nas células neoplásicas Myeloperoxidase (Polyclonal, Dako): POSITIVO
nas células neoplásicas. CD 235 GlicophorinA (Clone
JC159, Dako); NEGATIVO nas células neoplásicas FATOR 8 (Von WillebrandFactor/ Polyclonal, Dako); NEGATIV nas células neoplásicas CD 61 (Clone Y251, Dako); NEGATIVO nas celulas neoplásicas. CD 34, Class II (Clone QBEnd 10, Dako); POSITIVO nas cellulas neoplasicas. CKIT- CD 117 (Polyclonal, Dako): POSITIV em discreto número de celulas neoplásicas CD 56 (Clone 123C3, Dako); NEGATIVO nas celulas neoplasicas. Terminal DeoxynucleotidylTransferase -TdT (Polyclonal, Dako); POSITIVO em discreto número de células neoplásicas. Biópsia de medula óssea: o perfil imuno-histoquímico apoia o diagnostico de leucemia mieloide aguda citogenética: $(18,19)$

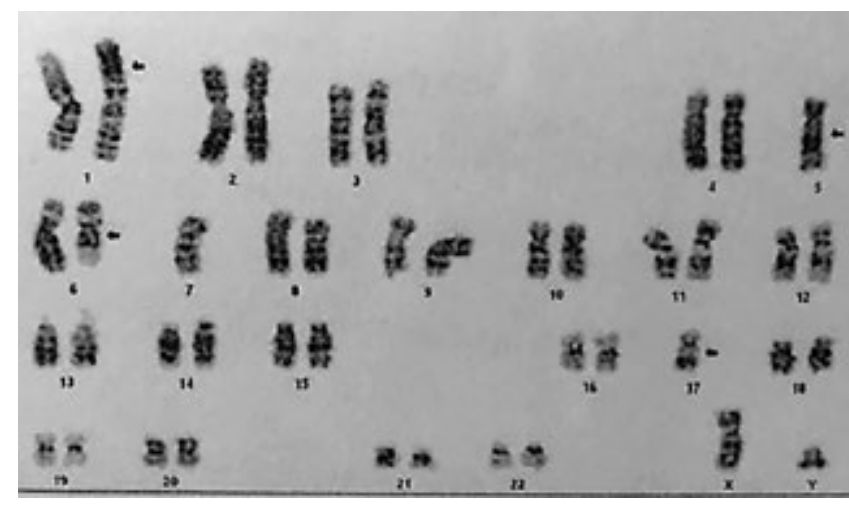

gura 1. Cariótipo masculino, 43, XY, $\mathrm{t}(1 \cdot 6)$ (p21:q14) $-5,-7,-17$. Alteração do cromossomo 7 não clonal.

\section{MONOSSOMIAS}

- Cromossomo 5: é a alteração cromossômica mais comum na SMD, é a deleção intersticial do braço longo do cromossomo 5 [del(5q-)], que pode atingir até $20 \%$ dos casos. A primeira está relacionada à SMD pós-terapia e associa-se a outras alterações como monossomia 7. A del(5q-) pode ocorrer tanto em céluas progenitoras mieloides como eritroides e há grande interesse em se identificar e definir um gene supressor tumoral presente nessa região. Mas, seja qual for o gene ou os genes de importância nessa questão que eventualmente venham a ser qualificados como comprometidos, a teoria do gene supressor tumoral deixa de explicar o evento inicial desencadeador da vantagem de crescimento das células progenitoras e, consequentemente, a hematopoese monoclonal. Portanto, outros mecanismos estão envolvidos e quiçá caiba aos genes supressores tumorais apenas o papel na progressão da doença e em parte dos casos.

Cromossomo 7: deleção completa ou parcial do braço longo do cromossomo ou monossomia 7 são achados frequentes em SMD. Também são comumente observados em associação a outras anomalias, como 5q-. Alterações do 7 são observadas em adultos com AREB ou AREBt e frequentemente correlacionadas à curta sobrevida ou evolução para leucemia.

Cromossomo 17: a síndrome de deleção do braço curto do cromossomo 17 (17p-) é habitualmente observada em SMD relacionada à terapia e raramente em SMD primária. $O$ isocromossomo do braço longo do 17 (i(17q)) corresponde, do ponto de vista hematológico, à presença de disgranulopoese, anomalia de pseudo-Pelger-Hüet, vacuolização de neutrófilos, eosinofilia, micromegacariócitos e evolução desfavorável. ${ }^{6}$ A p53 é uma fosfoproteína localizada no 17 p13.1 e regula a replicação do DNA, proliferação e morte celular, o que a torna um gene supressor

Biologia molecular: sem alterações (análise de mutação V617F do gene JAK2 e do gene mutação do
éxon 10 do gene MPL).

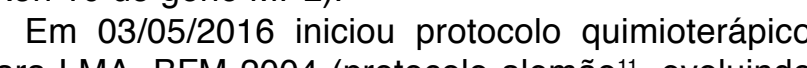
para LMA, BFM 2004 (protocolo alemão"1, evoluindo com aplasia medular severa, choque séptico e infecção fúngica (aspergilose pulmonar), porém não apresentou remissão da doença, com refratariedade ao tratamento.

Foi realizada HLA sem doador familiar compatível. Iniciou cuidados paliativos evoluindo para óbito em 03/08/2016

\section{DISCUSSÃO}

A trombocitose é definida como a contagem de plaquetas $>400.000 /$ LL. Pode ser dividida em 4 graus: leve (400 a $700 \times 10 \mathrm{~h} \mathrm{~L})$, moderada (700 a $\left.900 \times 10^{\wedge} 9 \mathrm{~L}\right)$, grave (900 a $\left.1000 \times 10 \wedge \mathrm{LL}\right)$ e extrema $\left(>1000 \times 10^{\wedge} \mathrm{g} \mathrm{L}\right)$. Pode ser reacional (TR) e essencial (TE).

ATrombocitose Reacional é secundária a múltiplas condiçoes ou patologias que promovem o aumento do $\mathrm{n}^{\circ}$ de plaquetas atraves de varios mecanismos fisiopatologicos. Achado relativamente comum na faixa etária pediatrica' ${ }^{12} \mathrm{e} 13,15$. E na maioria dos casos secundária a causas bem definidas, como infecções (bacteriana e viral), anemia, hipoxemia, inflamação, malignidade, estresse, trauma e esplenectomia (ver quadro-21 ). $72 \%$ dos casos de TR ocorrem em crianças $<2$ anos de idade e sem predomínio de sexo, dura cerca de algumas semanas e regride espontaneamente ${ }^{14}$
Tabela 1. Patologias ou condições associadas à trom bocitose reativa

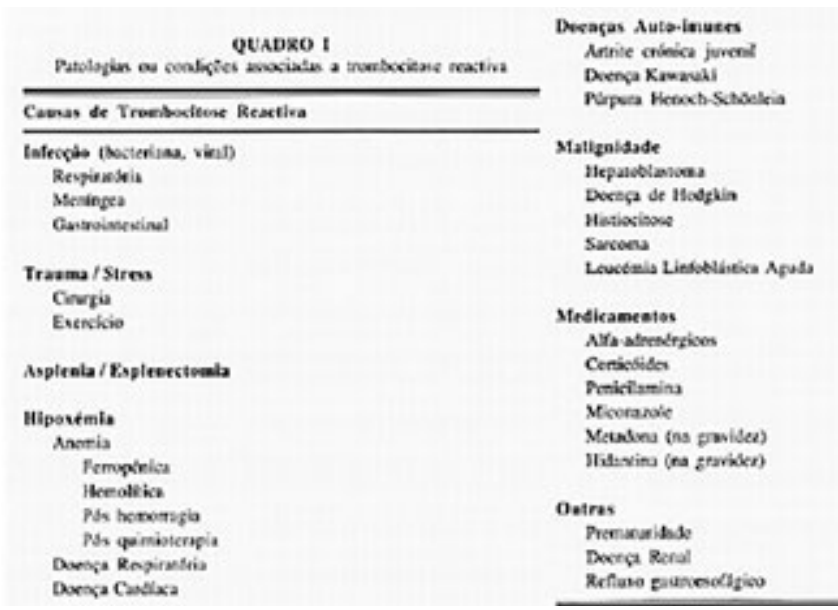

A fisiopatologia parece estar relacionada ao aumento da produção de interleucina 6, que acompanh processos inflamatórios, infecciosos ou malignos s.24 $^{4,24}$ Outras causas de TR estão relacionadas a estímulos alfa-adrenérgicos (trauma, cirurgia, exercícios), que promovem a liberação do pool plaquetário esplênico ${ }^{4}$. A asplenia, esplenectomia e medicações são causas de TR que podem mimetizar Trombocitose Essen-
cial $\left.\right|^{16,18,19,20 \text { e } 23}$.

Na TR, como é previsível a normalização do número plaquetário, com raras complicações, não justifica o tratamento com anticoagulantes ou antiagregantesplaquetarios. Quanto às plaquetas, acima de 1 milhão pode-se justificar profilaxia se estiverem associados outros fatores de risco (anemia ferropriva, arritmias cardiacas, imobilização, válvulas mecânicas, Kawasaki, doença cardíaca cianótica, Fontan, Shunt Blalok-Taussig e risco de trombose ${ }^{12,}$

Ao contrário da TR, a TE é extremamente rara em pediatria, sendo sua incidência cerca de $0,1 / 1000.000$ (H) e maior no sexo feminino (1,3 a 2/1 - F/M). É mais frequente apos 60 anos (1 a 2/100.000) e cerca de $1 / 3$ a 1/4 dos pacientes são assintomáticos. O quadro clínico é variável, podendo incluir perda de peso, cefaleia, febre, sudorese, prurido, ataques isquêmicos transitorios, amaurose fugaz, priapismo e eritromelalgia ${ }^{2,23}$. 
Tabela 2. Principais diferenças entre trombocitose reativa e trombocitemia essencial

\begin{tabular}{|c|c|c|}
\hline & Tromberitusais Euneriat & Troaboxitume Reastive \\
\hline 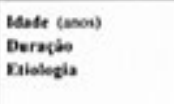 & 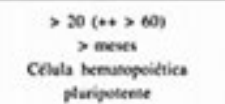 & 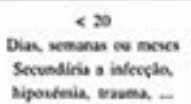 \\
\hline 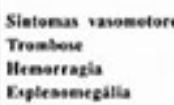 & $\ddot{\ddot{*}}$ & \\
\hline 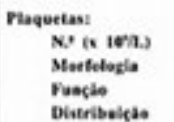 & 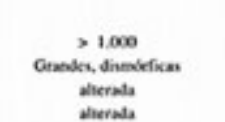 & $=0$ \\
\hline
\end{tabular}

A TE tem melhor prognóstico que outras doenças mieloproliferativas, com transformação leucêmica < $2 \%$ em pacientes não tratados (estatística na faixa etária adulta). O diagnóstico, além de anamnese e exame físico, requer exames complementares como hemograma com plaquetometria e confirmação por mielograma e biópsia de MO. A abordagem de uma trombocitose está esquematizada no gráfico $2^{24}$

Há necessidade de preenchimento de 4 dos critérios diagnósticos da classificação da OMS. Em relação ao estudo molecular e citogenético, 0 índice de alterações citogenéticas é cerca de $5 \%$,

As mais frequentes são trissomia do 8 e 9 , além da deleção $13 q$ e 20 p., sendo a mais comum na TE $(+8$, del (13q).

A ausência do cromossomo Philadelfia (rearranjo BCR-ABL) é fundamental para o diagnóstico da doença. Em $50 \%$ a $60 \%$ dos casos podem ocorrer a mutação JAK V617F ou do gene MPLW515L/W515K, sendo menos frequentes nas crianças que nos adultos. Especificamente no caso em questão com monossomia do 5,7 e 17, tem prognóstico reservado

Tabela 3. Critérios para o diagnóstico de trombocitemia essencial (OMS)

1. Plaquetometria $>450.000 / \mathrm{LL}$, sustentada 2. BMO com prolifferaçăo da linhagem megacariocitica com megacariocitos maduros aumentados em número e tamar Ausência de aumento significativo ou des

3. ausência de critérios OMS para PV, MF, LMC BCR/ABL1+. 3. ausência de critérios OMS para PV. MFF LMC BCR/ABL1+,
sindrome mielodisplásica (ausência de del(5q), t(3;3)(q21;q26).

sindrome mielodisplásica (ausência de del( $(5 q)$
inv(3)(q21; 926$)$ ) ou outra neoplasia mieloide
4. presença da mutaçă JAKV617F ou outras

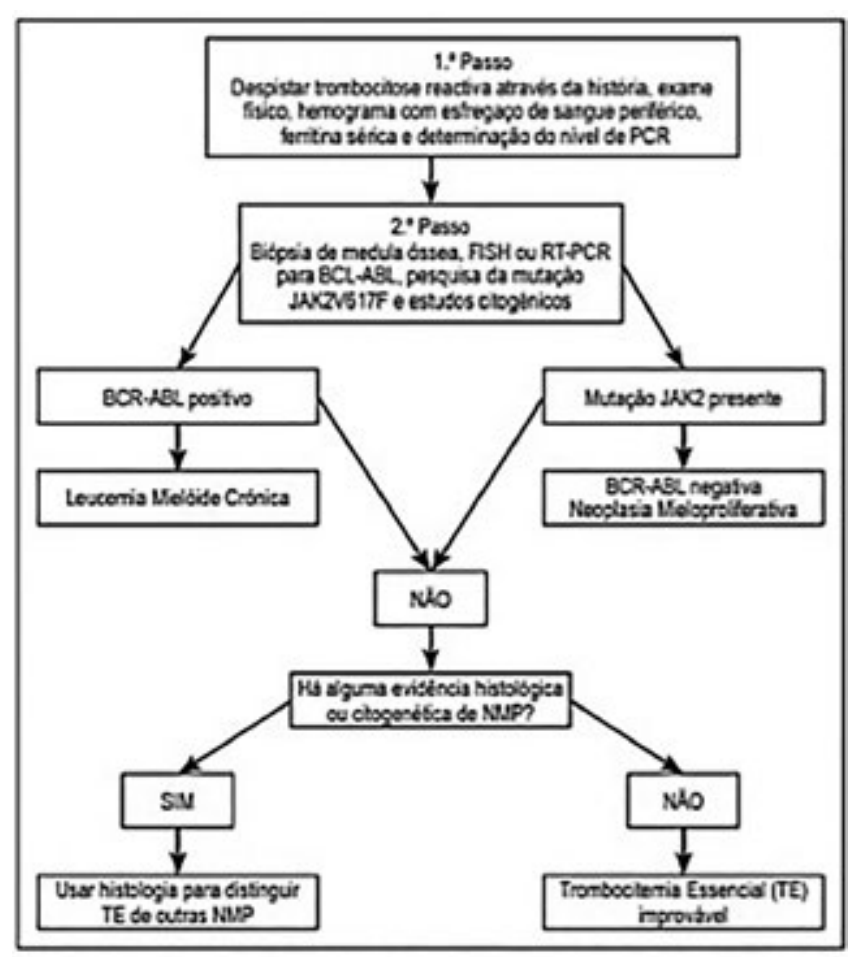

a p53 indutora de malignidades, como visto anteriormente. ${ }^{21,22}$

Com critérios clínicos de leucemia, foi iniciado protocolo alemão BFM2004 ${ }^{14}$ para LMA em 03/05/2016, evoluindo com quadro clínico de aplasia medular severa, cursando com choque séptico. Desenvolveu complicação pulmonar com aspergillose grave, diagnóstico por imagem e dosagem de galactomanana. Permaneceu em ventiliçăa mecânica até remissão do quadro com uso de Voriconazol. Evoluiu com recuperação medular já com mieloblastos, sem remissão clínica e hematológica.

Diante da ausência de resposta à indução quimioterápica, sem viabilidade de transplante de $\mathrm{MO}$ com risco de morte durante aplasia e alteração citogenética, cujo prognóstico era muito reservado, optou-se por tratamento paliativo. Houve progressão rápida da
doença e o paciente evoluiu para óbito em 03/08/2016.

\section{REFERÊNCIAS}

1. Vannucchi Am, Guglielmelli P, Tefferi A. Advances In Undestanding And Anagement Of Myeloproliferative Neoplasms. Ca Cancer J Clin. 2009;59(3):1791.

2. Laszlo J. Myeloproliferative Disorders (Mpd) Myelofibrosis, Myeloscrerosis, Extramedullary $\mathrm{He}$ matopoiesis, Undifferentiated Mpd, And Hemorrhagic Thrombocythemia. Seminhematol. 1975; 12(4):409-32. 3. Murphy S, lland H, Rosenthal Ds, Laszlo J. Essential Thrombocythemia: An Interim Report From Thepolycythemia Vera Study Group. Seminhematol. 1986;23(3):177-82.

4. Sutor Ah. Thrombocytosis In Childhood. Seminthrombhemostas 1995; 21: 330-9. 2. Chan Kw, Haikow Y, Wadsworth Ld. Thrombocytosis In Childhood: A Survey Of 94 Patients. Pediatrics 1989; 84: 1064-7.

5. Yohannan Md. Higgy Ke, Al-Mashhadani Sa E Al. Thrombocytosis: Etiologic Analysisof 663 Patients. Clinpediatr 1994; 33: 340-3.

6. Buss Dh, Cashell Aw, O'connor MI Et Al. Occurrence, Etiology And Clinicai Significance Of Extreme Thrombocytosis: A Study Of 280 Cases. Am.Med 1994 96: 247-53. 5. Kutti J. The Management Of Thrombocytosis. Eur J Haematol.

7. Tefferi A, Thiele J, Orazi A, Kvasnicka H, Barbui T, Hanson C, Et Al. Proposals And Rationale For Revision Of The World Health Organization Diagnostic Criteria For Polycythemia Vera, Essential Thrombocythemia, And Primary Myelonibrosis. Recommendations From An Ad Hoc International Expert Panel. Blood. 2007;15(4): 10927.

8. Tefferi A, Thiele J, Vardiman Jw. The 2008 World

Health Organization Classification System For Myeloproliferative Neoplasms: Order Out Of Chaos. Cancer 09;115(17):3842-7

9. Baxter Ej, Scott Lm, Campbell Pj, East C, Fourouclas N, Swanton.

10. Kapoor G., Correau H., Yu L. C. Essentia Lthrombocytemia In An Infant. J Pediatrhematolonco 1996; 18: 381-5. [ Links ]

11. Andrea B. Leite1 Herivaldo F. Silva 2 Otho Nogueira 3 trombocitemia Essencial. Rev. Bras. Hematol Hemoter. Vol. 23. №1. São José do Rio Preto. Jan Apr. 2001.

12. Jaffe, E.S., Harris, N.L., Stein, H., Vardiman, J.W. (Ed.). World Health Organization Classification O Tumours. Pathology Abd Genetics Of Tumours Of Haematopoietic And Lymphoid Tissues. Lyon: larc Press, 2001. 352p.

13.Paes, R.A.P., Vassallo, J., Alves, A.C., Menezes, Y., Siqueira, S.A.C., Aldred, V.L., Soares, F., Moraes, J.C. Classificação Da Organização Mundial De Saúde Para Neoplasias Dos Tecidos Hematopoiético E Linfoide: Proposta De Padronização Terminológica Em Língua Portuguesa Do Grupo De Hematopatologia Da Sociedade Brasileira De Patologia. Jornal Brasileiro De Patologia E Medicina Laboratorial (Rio De Janeiro), 38, N.3, P.237-239, 2002.

14. Aml-Bfm 2004author: Prof. Dr. Med. Ursula Creutzig ,Erstellt 2003/07/24, Last Modification 2012/06/28.

15. Tefferi A, Murray-N S, Hoagland Hc. Primary Thrombocythemia. Seminars In Oncology 1995; 22 (4): 16.

16. Yigal D, Alvin Z, Victor B. Essential Thrombocythemia In Children. J Pediatrhematoloncol 1999, 21 (5): 356-63.

17. Vora Aj, Lilleyman Js. Secondary Thrombocytosis. Arch.Dis.Child 1993; 63: 88-90

18. Sacchi S, Vinci G, Gugliotta LEt Al. Diagnosis Of Essential Thrombocythemia Atplateletcounts Betwe (00-600 X 109/L. Haematologica 2000; 85: 492-5.

19. Bauer J, Herrmann E Interleukin-6 In Clinicai

Medicine. Ann Hematol 1991; 62: 203-10.

20. Utsumi K, Takai Y, Tada T Et Al. Enhanced Production Of II-6 In Tumor-Bearingmice And Determination Of Cells Responsible For Its Augmented Production. J Immunol 1990; 145: 397-403

21. Chanet V, Tournilhac O, Dieu-Bellamy V Etal. solated Spleen A Genesis: A Rare.

22. Rosane I. Bittencourt, Karin Poncelet, Antonio Carlos C. Almeida, Katia Fassina Tor G. Onsten Tromachados nas células neoplásicas, que corroboram ainda mais a possibilidade de ter havido alteração citoge-
nética secundária, com produção de proteínas como

bocitose Essencial: O Que É Essencial Saber Essen- 
tial Thrombocytosis: Whatis Vital To Know Revista Brasileira De Hematologia E Hemoterapia.

23. Maria De Lourdes L. F. Chauffaille. Chromosomal Abnormalities In Myelodysplastic Syndrome Rev. Bras. Hematol. Hemoter. Vol.28. № 3.

24.Chauffaille, Maria De Lourdes L. F.. Neoplasias Mieloproliferativas: Revisão Dos Critérios Diagnósticos E Dos Aspectos Clínicos. Rev. Bras. Hematol. Hemoter. 2010, Vol.32, N.4, Pp.308-316.

25. Luís Gonçalves, Anabela Ferrão, Anabela Morais.Trombocitose Em Pediatria A Propósito De Um Caso De Trombocitemia Essencial.

26. Lopes, Raquel Et Al. Caso Hematológico. Nascer E Crescer [Online]. 2011,Vol. 20, N.4. p. 296-298.

1- Serviço de Onco-hematologia Pediátrica do HSI Endereço para correspondência:

jansamp@terra.com.br 